\title{
Reducing rectal injury in men receiving prostate cancer radiation therapy: current perspectives
}

This article was published in the following Dove Press journal:

Cancer Management and Research

28 July 2017

Number of times this article has been viewed

\author{
Nicholas A Serrano' \\ Noah S Kalman' \\ Mitchell S Anscher ${ }^{2}$ \\ 'Department of Radiation Oncology, \\ Virginia Commonwealth University - \\ Massey Cancer Center, Richmond,VA, \\ ${ }^{2}$ Department of Radiation Oncology, \\ University of Texas MD Anderson \\ Cancer Center, Houston, TX, USA
}

\begin{abstract}
Dose escalation is now the standard of care for the treatment of prostate cancer with radiation therapy. However, the rectum tends to be the dose-limiting structure when treating prostate cancer, given its close proximity. Early and late toxicities can occur when the rectum receives large doses of radiation therapy. New technologies allow for prevention of these toxicities. In this review, we examine the evidence that supports various dose constraints employed to prevent these rectal injuries from occurring. We also examine the use of intensity-modulated radiation therapy and how this compares to older radiation therapy techniques that allow for further sparing of the rectum during a radiation therapy course. We then review the literature on endorectal balloons and the effects of their daily use throughout a radiation therapy course. Tissue spacers are now being investigated in greater detail; these devices are injected into the rectoprostatic fascia to physically increase the distance between the prostate and the anterior rectal wall. Last, we review the use of systemic drugs, specifically statin medications and antihypertensives, as well as their impact on rectal toxicity.
\end{abstract}

Keywords: rectal toxicity, radiation therapy, prostate, prevention

\section{Introduction}

Radiation therapy for prostate cancer affords local control and survival benefits for men with varying stages of the disease. We now understand that dose escalation -through intensity-modulated radiation therapy (IMRT), brachytherapy (BT), or a combination of both IMRT and BT - allow even greater biochemical disease-free survival benefits. While this increased dose improves tumor kill, the tolerance of normal tissues limits the dose of radiation (RT) that can be safely delivered. ${ }^{1}$ The rectum, in most instances, tends to be the structure that limits the overall dose prescribed due to the potential toxicities.

Early rectal toxicities develop during the course of radiation therapy and typically persist for $<90$ days after the completion of treatment. These symptoms include loose stools or diarrhea, tenesmus, urgency, anorectal pain, irritation of hemorrhoids, and bleeding. These side effects are typically self-limited. However, more severe acute toxicities put patients at greater risk for long-term injuries from radiation therapy. ${ }^{2}$

Late RT-induced rectal toxicities are defined as those persisting or developing $>90$ days after therapy ends. Development of chronic proctitis (Figure 1) after pelvic RT has been reported in $5 \%$ to $40 \%$ of patients. ${ }^{3}$ Rectal bleeding is the most common late toxicity, which generally develops due to neovascularization and telangiectasias. ${ }^{4,5}$ Thickening and edema of the anterior rectal wall can result. Severely affected bowel can become fibrotic and ischemic, which results in more severe clinical manifestations, such as fistula formation, stricture, loss of compliance of the anal sphincter and even
Correspondence: Mitchell S Anscher University of Texas MD Anderson Cancer Center, 1515 Holcombe Blvd, Unit 1202, Houston, TX 77030-4009, USA

Tel + I 7137925905

Fax +17135636876

Email MSAnscher@mdanderson.org 


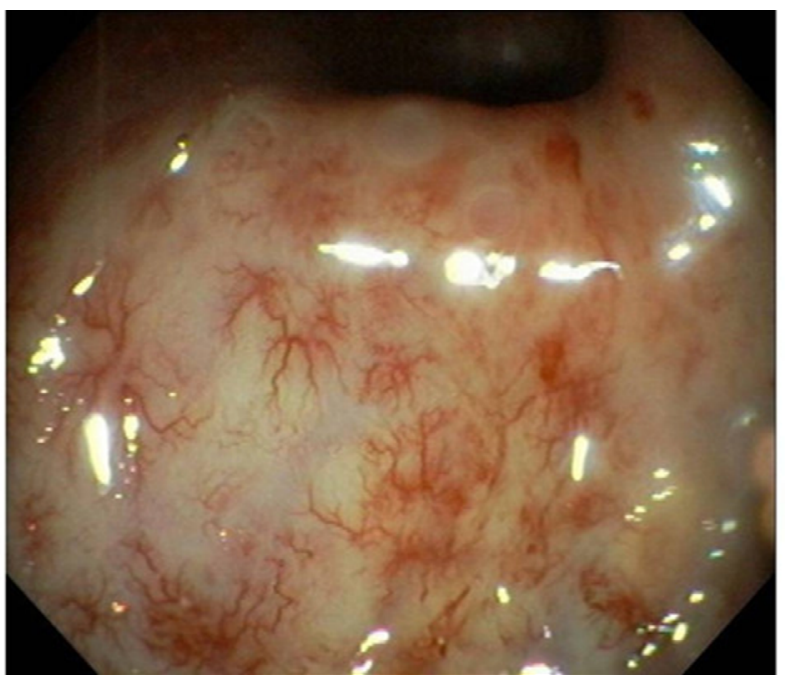

Figure I Example of radiation proctitis found on endoscopy. There are multiple hemorrhagic changes and telangiectasia seen after radiation therapy to the pelvis. Copyright (C2012. Reproduced from World Endoscopy Organization. Available from: http://www.endoatlas.org/index.php?page=results_jquery\&mstcat $=3 .{ }^{108}$

rectal perforation. Although few patients develop bleeding severe enough to necessitate transfusion, it can severely alter daily activities and affect the patient's quality of life (QOL).

In this article, we discuss methods that one can employ to prevent these toxicities.

\section{Incidence}

Advances in technology have resulted in improved RT dose delivery which, in turn, has improved biochemical diseasefree survival. ${ }^{6}$ There are various approaches to increasing the dose the patient receives, including high-dose photons using IMRT, ${ }^{6}$ charged particles (protons), ${ }^{7}$ and combinations of external beam and BT. ${ }^{8,9}$ Despite increased dose conformity, rectal injuries have not been eliminated, owing to the proximity of the rectum to the prostate.

Giordano et $\mathrm{a}^{10}$ analyzed the SEER database for claims of gastrointestinal (GI) diagnoses 6-60 months after RT ( $\mathrm{n}=$ $24,130)$, and compared this to a group of men with prostate cancer treated without RT $(\mathrm{n}=33,835)$. They found that late lower GI toxicity after RT may be more common than previously reported. Rates of GI diagnoses were $19 \%$ higher in the RT group, with bleeding being the most common diagnosis ( $40 \%$ vs $18-20 \%$ in patients treated without RT). Lower endoscopies were performed in $32 \%$ of RT patients versus $12 \%$ of patients treated with radical prostatectomy. These patients were treated between 1992 and 1999; thus, today's improved techniques of irradiation (IMRT and BT) might reduce the risk of GI injury, but not eliminate it. Conversely, these values may more accurately estimate the risk of GI injury throughout the radiation oncology community, as opposed to what is reported from highvolume centers. Table 1 summarizes data on the incidence of late rectal injury after various types of radiotherapy for prostate cancer.

\section{IMRT}

Dose escalation has become the standard of care for patients with prostate cancer after randomized trials showed improvement in disease control with increasing RT dose., ${ }^{71-13}$ The primary clinical problem radiation oncologists face is the ability to achieve high doses of irradiation at the tumor site without causing severe complication in normal tissues that are in the path of the treatment beam. Over the past two decades, there have been significant advances in technology that now allow three-dimensional (3D) tailoring of RT dose delivery as well as proton therapy (Figure 2). IMRT is a technique that uses multiple beam angles and robotically controlled beam-shaping devices located within the linear accelerator to conform the dose to the prostate as closely as possible. This allows for sparing of the nearby normal structures - in this case, the bladder and/or rectum.

The utilization of IMRT in the treatment of prostate cancer has led to decreases in rectal injury. An example of this comes from a study by Zelefsky et $\mathrm{al}^{14}$ in which they examined 1,571 patients treated with 3DCRT or IMRT. The doses ranged from 66 to $81 \mathrm{~Gy}$ and all patients who received IMRT were prescribed $81 \mathrm{~Gy}$. With a median follow-up of 10 years, they found that the incidence of Grade $\geq 2$ GI toxicity was significantly lower at $5 \%$ in the IMRT group versus $13 \%$ in the 3DCRT group $(P<0.0001)$, despite the fact that patients in the IMRT group received higher doses of RT to the prostate. Alicikus et a $\mathrm{l}^{15}$ examined 10 -year outcomes of 170 patients who received 81 Gy RT using a 5-field IMRT technique. They found that late Grade 2 GI toxicity occurred in 4 patients (2\%), and late Grade 3 GI toxicity occurred in 2 patients (1\%). Among patients who developed late Grade 2 GI toxicity, 2 developed rectal bleeding at a median of 24.5 months after therapy completion. No Grade 4 rectal toxicities were noted. The 10-year incidence of late Grade 2 GI toxicity was $3.7 \%$, much lower than in historical controls using 3DCRT. ${ }^{11,13,16}$

Whereas IMRT has improved the ability to safely dose escalate in patients with prostate cancer, IMRT per se cannot take sole credit for reduction in toxicities. Given that larger doses are prescribed in prostate IMRT plans, the margins around the clinical target volume are significantly reduced as compared to 3DCRT plans and accurate image guidance is required to safely deliver these treatments. 
Table I Summary of literature regarding incidence of late rectal injury

\begin{tabular}{|c|c|c|c|c|}
\hline Author & Treatment & Dose & Incidence & Comments \\
\hline Vargas et $\mathrm{al}^{30}$ & IGRT & 75.6 Gy median & $20 \%$ Grade $\geq 2$ & Cumulative incidence \\
\hline Sarosdy ${ }^{93}$ & $\mathrm{BT} \pm \mathrm{EBRT}$ & Various & $26 \%$ (3\% Grade 4$)$ & Crude incidence \\
\hline Akimoto et al ${ }^{94}$ & EBRT & 69 Gy; 3 Gy/fraction & $25 \%$ Grade $\geq 2$ & Cumulative incidence \\
\hline Rancati et $\mathrm{al}^{29}$ & $3 \mathrm{D}$ & 64-79.2 Gy & $8 \%$ Grade $\geq 2$ & Crude incidence \\
\hline Lee et a $9^{95}$ & $3 \mathrm{D}$ & 70-74 Gy & $24 \%$ Grade $\geq 2$ & Cumulative incidence \\
\hline Sherertz et $\mathrm{al}^{96}$ & $\mathrm{EBRT}+\mathrm{BT}$ & Various & $7.5 \%$ & Crude incidence \\
\hline Tucker et $\mathrm{al}^{97}$ & $3 \mathrm{D}$ & 78 Gy & $23 \%$ Grade $\geq 2$ & Crude incidence \\
\hline Waterman and Dicker ${ }^{98}$ & BT & I50 Gy & $10 \%$ & Crude incidence \\
\hline Yoshioka et al ${ }^{99}$ & HDR BT & 48-54 Gy, 6 Gy/fraction & $12 \%$ & Crude incidence \\
\hline Albert et al ${ }^{100}$ & $\mathrm{BT} \pm \mathrm{EBRT}$ & Various & $8 \%-30 \%$ Grade $\geq 2$ & Actuarial \\
\hline Ryu et $\mathrm{al}^{101}$ & $3 \mathrm{D}$ & $79.2 \mathrm{~Gy}$ & $\sim 20 \%$ Grade $\geq 2$ & Estimated \\
\hline Michalski et $\mathrm{al}^{37}$ & $3 D$ & 74 Gy & $\sim 20 \%$ Grade $\geq 2$ & Estimated \\
\hline Skwarchuk et al ${ }^{102}$ & $3 \mathrm{D}$ & $\geq 75.6 \mathrm{~Gy}$ & $17 \%$ Grade $\geq 2$ & Actuarial \\
\hline Lee et $\mathrm{al}^{46}$ & 3D, IMRT & $\begin{array}{l}73.8 \text { Gy (conventional) vs } 70 \text { Gy } \\
\text { (hypofractionated) }\end{array}$ & $14 \%$ vs $22 \%$, Grade $\geq 2$, respectively & Cumulative incidence \\
\hline Hoffman et $\mathrm{al}^{103}$ & 3D, IMRT & $\begin{array}{l}75.6 \text { Gy (conventional) vs } 72 \text { Gy } \\
\text { (hypofractionated) }\end{array}$ & $20 \%$ vs $37 \%$, Grade $\geq 2$, respectively & Cumulative incidence \\
\hline Pollack et al ${ }^{104}$ & IMRT & $\begin{array}{l}76 \text { Gy (conventional) vs } 70.2 \text { Gy } \\
\text { (hypofractionated }\end{array}$ & $23 \%$ vs $18 \%$, Grade $\geq 2$, respectively & Crude incidence \\
\hline Katz and Kang ${ }^{105}$ & SBRT & $35-36.25$ Gy & 4\% Grade 2 & Actuarial \\
\hline Chen et al ${ }^{106}$ & SBRT & $35-36.25 \mathrm{~Gy}$ & I\% Grade 2 & Actuarial \\
\hline King et al ${ }^{107}$ & SBRT & $36.25 \mathrm{~Gy}$ & $2 \%$ Grade 2 & Cumulative incidence \\
\hline Kim et a $\mathbf{7}^{79}$ & SBRT & $45,47.5$, and $50 \mathrm{~Gy}$ & $\begin{array}{l}45 \text { Gy- } 7 \% \text { Grade } \geq 2,47.5 \text { Gy- } 33 \% \\
\text { Grade } \geq 2,50 \text { Gy- } 33 \% \text { Grade } \geq 2\end{array}$ & Cumulative incidence \\
\hline
\end{tabular}

Abbreviations: IGRT, image-guided radiation therapy; 3D, three-dimensional conformal radiation therapy; EBRT, external beam radiation therapy; BT, brachytherapy; HDR, high dose rate brachytherapy; IMRT, intensity-modulated radiation therapy; SBRT, stereotactic body radiation therapy.

\section{Image-guided radiation therapy}

One of the most crucial aspects of patient treatment involves the setup and target localization before each treatment fraction. New technologic advances have dramatically improved the accuracy of IGRT. ${ }^{17-19}$ These techniques include daily CT scans acquired by an imaging system mounted on the linear accelerator, ${ }^{20}$ radio-opaque fiducial markers placed in the prostate and imaged with daily X-rays, ${ }^{21}$ and radiofrequency beacons that can be implanted, similar to fiducials. ${ }^{22}$ The position of those radiofrequency beacons can be electronically determined and allows real-time monitoring of the position of the prostate during therapy. This helps reduce rectal injury as the radiation beam can be turned off if the target beacons move outside a predetermined location. Rajendran et $\mathrm{al}^{23}$
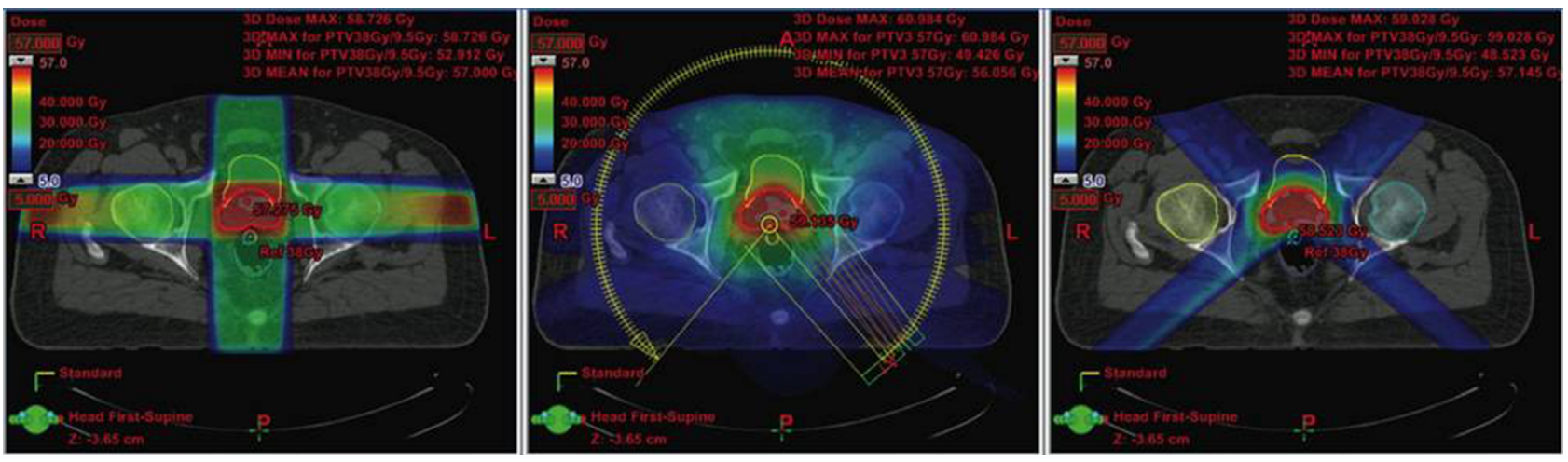

Figure 2 Comparison of treatment plans in a patient with prostate cancer. Shown is a typical slice of the planning CT in the pelvis with different radiation plans calculated: left image: Conventional 4-field 3D-conformal plan; middle image: intensity-modulated volumetric arc plan, right image: 4-field proton plan. The arrows show the target contour (prostate, red), the rectum (black with inflated rectum balloon), and the hips. Red signifies high dose volume, green intermediate dose volume, and blue low dose volume. The rectum is the major organ that has to be spared from radiation in the case of prostate cancer. To protect the rectum, an endorectal balloon is inserted before every radiation fraction and inflated with air. The rectum balloon serves to move major parts of the rectal wall away from the prostate and the high dose volume. The volumetric arc plan spares the rectum much better and conforms the dose better to the prostate than the 3D plan. In comparison, the proton plan shows equal target coverage as the VMAT plan, but much less dose delivery to the surrounding tissue, especially the rectum and both hip bones. Copyright @2013. Swiss Physical Society. Image and figure caption reproduced from Lang S and Riesterer O. Progress in Physics: Modern Techniques in Radiation Oncology. SPG Mitteilungen. 20I3;4I(36): I9-22. ${ }^{\circ 9}$ 
evaluated dosimetric consequences of daily isocenter corrections during prostate cancer radiation therapy of 28 men using an electromagnetic beacon system. They calculated the daily corrections in positioning based on real-time data obtained by the beacons during delivery of 79.2 Gy. They reported that, without daily electromagnetic localization, $70 \%$ of the rectum received an additional $10 \mathrm{~Gy}$.

To investigate the importance of IGRT in prostate radiation therapy, Chung et $\mathrm{al}^{24}$ examined 25 patients treated with high-dose IMRT. Radio-opaque fiducials were placed into the prostate in 15 patients and were compared to 10 patients without fiducials. The planning target volume dose coverage was not significantly different between the two groups. However, the volume of rectum and bladder receiving $\geq 40$, $\geq 60$, and $\geq 70$ Gy were all significantly less using IGRT ( $P$ $<0.001)$. This correlated with lower acute RTOG Grade 2 rectal toxicities $(80 \%$ vs $13 \%, P=0.004)$.

\section{Dose-volume histograms (DVHs)}

Given the increased use of IMRT, quantitative assessments of the doses delivered to normal organ volumes have become increasingly important. With the use of 3D planning, reliable dose-volume relationships have been developed to reduce toxicity. This has also led to the establishment of normal tissue complication probability (NTCP) models to allow radiation oncologists to protect normal tissues by setting predetermined dose-volume constraints at the time of RT treatment planning.

Fiorino et $\mathrm{al}^{25}$ reviewed the existing literature on NTCP models and dose constraints of pelvic organs and related these constraints to specific pelvic toxicities. The authors found relatively consistent agreement among investigations on the DVH relationships to rectal bleeding. Additionally, the strict application of rectal dose-volume constraints in high-dose IMRT translated into a greatly reduced rate of bleeding. ${ }^{25-32}$ After reviewing available literature, they found that keeping the volume of rectum receiving $>70 \mathrm{~Gy}$ and $>75$ Gy (V70Gy and V75Gy) to $<25 \%$ and $<5 \%$, respectively, reduced the incidence of late rectal bleeding. ${ }^{33-35}$ In addition to keeping the high-dose volumes (V70 and V75) as low as possible, the moderate dose volumes (V40-V50) can also play a key role in the development of rectal bleeding. The authors found an increased incidence of rectal bleeding when large portions of the rectum received 40-50 Gy.

Two large clinical trials reported correlations between rectal DVHs and rectal incontinence. ${ }^{32,36}$ The authors suggested keeping the V40Gy to $<65-70 \%$ to reduce the risk of chronic late incontinence, defined as using pads, to $<1.5 \%$. Others reported that large volumes $(80-90 \%)$ of the rectum receiving 40-50 Gy were predictive of late incontinence. ${ }^{36}$ They hypothesized that the mechanism involved the reduced ability of the rectal mucosa to absorb water.

The majority of dose-volume investigations have focused on late rectal toxicities and the doses that may predict for these events. While fewer studies examined acute rectal toxicity, they are equally important as acute rectal injuries predict for chronic injuries and can lead to worsened patient QOL and treatment interruptions. Michalski et $\mathrm{al}^{37}$ reported on 262 patients that were enrolled on RTOG 9406, a phase I-II dose escalation trial using 3DCRT for localized prostate cancer. They used a rectal constraint of V65Gy $<20 \%$. They found that acute toxicity was remarkably low at 3\%, with no Grade 4 or 5 acute toxicities reported. Peeters et al $^{38}$ examined dose-volume data and correlated this to acute toxicity. They found that both intermediate and high doses delivered to the rectum correlated with GI toxicity. They also found that the rectal lengths irradiated to doses greater than 5, 15, and 30 Gy were correlated with acute side effects.

In a recent study, Schaake et $\mathrm{al}^{39}$ developed multivariable NTCP models for late rectal bleeding, stool frequency, and fecal incontinence in men that received pelvic radiation therapy for prostate cancer. They prospectively analyzed 262 patients. Anorectal toxicity was assessed, and the authors identified and contoured different anatomical subregions within and around the anorectum for dosimetric analyses. They found that rectal bleeding was associated with the anorectum V70. Fecal incontinence was associated with the external sphincter V15 and the iliococcygeal muscle V55. Moreover, they found that increases in stool frequency were associated with the iliococcygeal muscle V45 and the levator ani V40. They did not find significant associations for rectal pain.

Given that most of the aforementioned studies defined dose-volume constraints based primarily on 3D-conformal RT, Mirjolet et $\mathrm{al}^{40}$ studied whether these same constraints applied to IMRT. They retrospectively examined 180 patients with prostate cancer treated with IMRT and looked at standard dose-volume-specific endpoints, specifically the volume of rectum receiving from 25 to 75 Gy (V25-V75), expressed in percentages (\%) and in cubic centimeters (cc). They then calculated the area under the DVH curve between 25 and $50 \mathrm{~Gy}$ for the rectum $\left(\mathrm{rAUC}_{25-50}\right)$, which they hypothesized would more accurately predict risk of rectal events. The rAUC $_{25-50}$ calculated in cubic centimeters correlated with any grade $\geq 1$ acute GI toxicity $(P=0.028)$. Based on this, the 
authors recommended that the $\mathrm{AUUC}_{25-50}$ of the entire rectum should not exceed $794 \mathrm{cc}$.Gy.

The aforementioned studies examined the association between rectal injury and dose to the rectum using whole organ at risk (OAR) models, where the entire rectum is assumed to be homogeneously radiosensitive. However, Dréan et $\mathrm{al}^{41}$ recently published a unique analysis where the authors set out to identify rectal subregions at risk (SRR) that correlated with rectal bleeding and compared these SRRs to conventional whole-organ rectal DVHs. The authors prospectively treated 173 patients with localized prostate cancer and generated 20 geometric rectal delineations for all patients. These delineations included the whole rectum, anterior hemirectum, craniospinal rectum thirds (inferior, medium, and superior), the part of the rectum directly in front of the prostate, and the portions of the rectum localized at $<5,10$, 15 , and $20 \mathrm{~mm}$ from the prostate surface. DVHs were then calculated in three types of rectal subregions: "geometric", "personalized", obtained by non-rigid registration followed by voxel-wise statistical analysis (SRRp); and "generic", mapped from SRRps, located within $8 \times 8$ rectal subsections (SRRg). Through this non-rigid registration and voxel-wise statistical analysis, the authors were able to identify a specific SRRp for each patient representing $<4 \%$ of the absolute rectal volume as a whole. These rectal subregions were primarily located in the subprostatic anterior hemirectum and upper part of the anal canal. The dose delivered to these subregions in patients suffering from rectal bleeding was almost 4 Gy greater (up to $6.8 \mathrm{~Gy}$ ) than for patients without rectal bleeding.

\section{Moderate hypofraction}

Conventional fractionation for prostate cancer involves delivering daily fractions of 1.8-2 Gy per day over 7-9 weeks. Recent advances in radiation therapy technologies have renewed interest in hypofractionation - defined as delivery of daily fractions of 2.5-10 Gy. Moderate hypofractionation (MH) has been defined as < 4 Gy per fraction and, recently, has been tested in prospective trials against conventional fractionation. The linear quadratic model describes the association of the total isoeffective dose and fraction size. The model uses two constants: $\alpha$ and $\beta$, and the ratio $\alpha / \beta$ is inversely related to the effect of changes in fraction size on normal and malignant tissues. Most cancers and acute normal tissue reactions are believed to have high $\alpha / \beta$ ratios of $10 \mathrm{~Gy}$. However, prostate cancer has been suggested to have an $\alpha / \beta$ of $1.5 \mathrm{~Gy} .{ }^{42,43}$ This is lower than the 3 Gy reported for the late reactions of most normal tissues, including the rectum. ${ }^{44} \mathrm{MH}$ also has advantages of increased convenience for the patient and a lower cost burden for the health-care system.

Recently, four large randomized trials have been published that compared standard fractionation (SF) to $\mathrm{MH}$. The trials were $\mathrm{CHHiP},{ }^{45}$ RTOG 0415, ${ }^{46}$ PROFIT, ${ }^{47}$ and HYPRO.${ }^{48}$ The first three trials were non-inferiority trials and the doses in the $\mathrm{MH}$ arms ranged from 57 to 70 Gy administered in 2.5-3.4 Gy per fraction. The HYPRO ${ }^{48}$ study was a superiority trial and the patients in the $\mathrm{MH}$ arm received 64.6 Gy in 3.4 Gy per fraction. Overall, these studies demonstrated that the safety and efficacy of $\mathrm{MH}$ was similar to that of SF. However, the $\mathrm{MH}$ arm in the HYPRO study was not superior to conventional radiotherapy with respect to 5-year relapse-free survival.

The CHHiP trial ${ }^{45}$ was the largest non-inferiority randomized study of $\mathrm{MH}$ and randomized 3,216 patients to 74 Gy/37 fractions/7.4 weeks, 60 Gy/20 fractions/4 weeks, or $57 \mathrm{~Gy} / 19$ fractions/3.8 weeks, with treatment delivery using IMRT. After a median follow-up of 62.4 months, acute RTOG GI toxicity had become similar in each arm by 18 weeks, it peaked earlier in the hypofractionated arm (4-5 weeks) compared to the control arm (7-8 weeks). Early Grade $\geq 2$ GI toxicity was significantly higher in the hypofractionated arms; it was $25 \%$ in the $74-G y$ arm, $38 \%$ in the 60 -Gy arm $(P<0.0001)$, and $38 \%$ in the $57-\mathrm{Gy}$ arm $(P<0.0001)$. The 5 -year clinician and patient-reported side effects were not significantly different. RTOG Grade $\geq 2$ GI toxicity was reported at 13.7, 11.9, and $11.5 \%$ in the $74-, 60-$, and 57-Gy arms respectively. Comparison of the 60- and 57-Gy arms revealed a slightly higher rate of cumulative LENT-SOM Grade $\geq 2$ GI toxicity [hazard ratio (HR) 1.39, 95\% confidence interval (CI) $1.14-1.70 ; P=0.001]$.

The PROFIT trial ${ }^{47}$ enrolled 1,206 men and randomized them to $60 \mathrm{~Gy} / 20$ fractions/4 weeks versus $78 \mathrm{~Gy} / 39 \mathrm{frac}-$ tions/7.8 weeks. The median follow-up was 6 years. The proportion of patients with acute Grade $\geq 3$ toxicity was low in both arms. Late Grade $\geq 3$ toxicity was not significantly different between groups; interestingly, there was a trend toward higher levels in the standard arm $(P=0.10)$. There was a significant increase in acute Grade $\geq 2$ toxicity in the MH $\operatorname{arm}(P=0.003)$. However, the late Grade $\geq 2$ toxicity was significantly increased in the standard arm $(P=0.006)$. The RTOG 0415 study $^{46}$ randomized 1,092 patients with lowrisk disease to $73.8 \mathrm{~Gy} / 41$ fractions/8.2 weeks or $70 \mathrm{~Gy} / 28$ fractions/5.6 weeks. The median follow-up was 5.8 years. The acute side effects did not differ significantly in the two arms of the study. Late grades 2 and 3 GI adverse events were approximately $60 \%$ more likely in men who were assigned to treatment with $\mathrm{MH}(\mathrm{RR}, 1.55-1.59)$. 
In contrast to RTOG $0415,{ }^{46} \mathrm{CHHiP}^{45}$ reported no difference in late toxicity, whereas $\mathrm{PROFIT}^{47}$ reports a lower rate of late toxicity in the MH arm. These differences may be due to the biologically effective dose (BED) in the MH and control arms of each individual study as explained by Benjamin et al. ${ }^{49}$ Assuming an $\alpha / \beta$ of 3.0 Gy for bladder/rectum, the BED in the MH arm is higher than in the control arm in RTOG $0415^{46}$ ( 128 Gy vs $118 \mathrm{~Gy}$ ), similar to the control arm in $\mathrm{CHHiP}^{45}$ (120 Gy vs $123 \mathrm{~Gy}$ ), and lower than the control arm in PROFIT $^{47}$ (120 Gy vs 130 Gy).

The HYPRO study ${ }^{48}$ is the largest of the MH superiority studies. HYPRO randomized 804 patients with intermediateor high-risk disease to $64.6 \mathrm{~Gy} / 19$ fractions/ 3 fractions per week $/ 6.5$ weeks or $78 \mathrm{~Gy} / 39$ fractions $/ 5$ fractions per week $/ 7.8$ weeks, respectively. The cumulative incidence for acute Grade $\geq 2$ GI toxicity was significantly higher (OR 1.6; $P=0.0015$ ) in the $\mathrm{MH}$ arm $(42 \%, 95 \%$ CI $37.2 \%-46.9 \%)$ compared to control $(31.2 \%, 95 \%$ CI $26.6 \%-35.8 \%)$. There were no statistically significant differences in cumulative Grade $\geq 3$ late GI toxicity between the two arms (2.6\% vs $3.3 \%)$.

\section{Endorectal balloons}

Endorectal balloons are silicon or latex devices that are filled with either air or water and are inserted into the rectum just prior to an RT treatment. These balloons have been utilized during radiation therapy as prostate immobilizers to reduce interfraction and intrafraction variations in prostate position, thus facilitating treatment with tighter margins. D'Amico et $a l^{50}$ evaluated intrafraction prostate motion by obtaining CT-images at 1-minute time intervals, both with and without an air-filled $(60 \mathrm{cc})$ endorectal balloon in place. The mean displacement of the prostate gland with the endorectal balloon present versus that when absent was $1.3 \mathrm{~mm}$ (range 0-2.2 $\mathrm{mm}$ ) versus $1.8 \mathrm{~mm}$ (range $0-9.1 \mathrm{~mm}$ ) at 2 minutes, respectively, and both were statistically significant $(P=0.03)$. The maximum displacement in any direction (anterior-posterior, superior-inferior, or right-left) when the endorectal balloon was inflated versus absent was reduced to $\leq 1 \mathrm{~mm}$ from $4 \mathrm{~mm}$.

Other investigators looked at larger endorectal balloons (100 cc) and studied the interfraction motion throughout a prostate RT course. Two groups of investigators using 100 $\mathrm{cc}_{\text {balloon }}{ }^{51,52}$ found small interfraction displacements when the device was inserted. The largest mean displacement was in the superior-inferior direction and measured $0.92 \mathrm{~mm}$. Additionally, no organ displacement was seen during normal breathing with the balloon inserted. Given this limited prostate motion, smaller treatment margins were advised when using the balloon. van Lin et a $1^{53}$ investigated the effect of an endorectal balloon on the day-to-day interfraction prostate gland motion. They compared prostate displacements daily in three orthogonal directions with portal images in patients with the balloon, compared to measurements made without the balloon. They found that prostate displacements were essentially the same for both groups: $1.3-1.8 \mathrm{~mm}$. The mean 3D displacement was reduced to 2.8 and $2.4 \mathrm{~mm}$ for the balloon and no-balloon groups, respectively. The random interfraction displacements, relative to the treatment isocenter, were not reduced by the endorectal balloon and remained nearly unchanged in all three directions: $3.1 \mathrm{~mm}$ left-right, $2.6 \mathrm{~mm}$ superior-inferior, and $4.7 \mathrm{~mm}$ anterior-posterior. They concluded that off-line corrections using fiducial markers were effective at reducing the systematic prostate displacements and that endorectal balloons did not further reduce interfraction prostate motion. A similar conclusion was made by a separate group of investigators that prospectively analyzed weekly portal images of 15 patients undergoing external-beam radiotherapy with endorectal balloons. ${ }^{54}$ Thus, there are conflicting reports on the utility of these balloons.

Endorectal balloons also effect the dosimetry of radiation therapy plans, and many groups of investigators have studied this dosimetric impact. In 3DCRT plans, smaller endorectal balloons ( $40 \mathrm{cc}$ air-filled) reduced the high-dose exposure to the posterior rectal wall. ${ }^{55}$ This finding was largely attributed to the increased distance between the prostate and the posterior rectal wall. However, when the seminal vesicles (SVs) were included in the target volumes, only intermediate-sized balloons $(60 \mathrm{cc})$ led to reductions in intermediate and high posterior rectal wall doses. ${ }^{56,57}$ These results were reproduced even when SVs were included in the treatment field. ${ }^{58}$

van Lin et al performed a unique study comparing endorectal balloons of various sizes. They studied 40,80 , and $100 \mathrm{cc}$ balloons, versus no balloons, in patients undergoing four-field 3DCRT and IMRT treatments. ${ }^{59}$ They analyzed 284 treatment plans and examined the rectal wall mean dose, the rectal wall NTCP, and the absolute rectal wall volumes exposed to $\geq 50$ Gy (V50) and $\geq 70$ Gy (V70). In patients receiving 3DCRT, the endorectal balloons significantly reduced the measured parameters and the 80 and $100 \mathrm{cc}$ balloons performed better than the $40 \mathrm{cc}$ balloons. In IMRT patients, no significant reductions in rectal wall dose parameters could be demonstrated for any of the balloons.

Because IMRT has become the standard of care for prostate cancer, these results pertaining to 3DCRT are less relevant. In contrast to the van Lin et al analysis, ${ }^{59}$ the previously mentioned study by Patel et $\mathrm{al}^{58}$ found that the $100 \mathrm{cc}$ 
balloons reduced the absolute rectal wall V60, V65, and V70 in patients receiving IMRT. The authors compared rectal dose sparing with endorectal balloons in patients treated with 3DCRT plans to those with IMRT plans, both with and without balloons. They found that the rectal dose sparing in a 3DCRT with a balloon was as conformal as an image-guided IMRT approach without a balloon. However, inclusion of a balloon with IMRT produced further rectal sparing.

The majority of published studies focus on the dosimetric effects of endorectal balloons, but data on patient- and physician-reported toxicities with the use of these balloons is scarce. van Lin et al ${ }^{60}$ compared 24 patients treated with versus 24 patients irradiated without a $40 \mathrm{cc}$ endorectal balloon. These patients were treated with 3DCRT to $67.5 \mathrm{~Gy}$ and subsequently underwent rectosigmoidoscopy at multiple time points after radiation therapy. A total of 146 endoscopies and 2,336 mucosal areas were analyzed. The endorectal balloon significantly reduced the rectal wall volume that was exposed to doses $>40 \mathrm{~Gy}$, and late rectal toxicity (grade $\geq 1$ ) was reduced significantly. Telangiectasias were most frequently seen and appeared after 6 months. At 1 and 2 years, there were significantly fewer high-grade telangiectasias observed in the endorectal balloon group in mucosal areas exposed to doses $>40$ Gy. The authors found that grades 1-3 late rectal bleeding occurred in $33 \%$ of the patients without the balloon versus $13 \%$ with the balloon. However, given the small number of patients in the study, this difference did not reach statistical significance. While these results are promising, larger prospective trials, especially with IMRT techniques, are needed to confirm these reductions in the rectal toxicity with the use of the endorectal balloons.

\section{Tissue spacers}

Given the close proximity of the anterior rectal wall to the prostate, many investigators have begun studying the use of bioabsorbable spacers to physically increase the distance from the prostate to the rectum. The rectoprostatic fascia (or Denonvilliers' fascia), is a membrane that separates the prostate and bladder from the rectum. This potential space is accessed to inject bioabsorbable material directly posterior to the prostate, thereby increasing the distance from the prostate to the anterior rectal wall. To date, various bioabsorbable materials have been injected between the prostate and rectum and have successfully increased the separation between the rectum and prostate. ${ }^{61}$ This procedure is typically done prior to starting a course of external beam radiation therapy (EBRT) and can also be undertaken simultaneously with a BT implant or fiducial marker placement. Hyaluronic acid, ${ }^{62}$ human collagen,${ }^{63}$ interstitial biodegradable balloons,${ }^{64}$ and synthetic polyethylene glycol (PEG) hydrogel ${ }^{65,66}$ have been the main materials studied in small trials evaluating safety and its subsequent degradation over time.

Synthetic PEG hydrogels are now FDA approved for used in prostate cancer. Strom et al ${ }^{66}$ treated 100 patients of prostate cancer with high dose rate (HDR) BT with or without IMRT. The patients received a transrectal ultrasound (TRUS)-guided transperineal injection of $10 \mathrm{~mL}$ PEG hydrogel DuraSeal ${ }^{\mathrm{TM}}$ (Covidien, Mansfield, MA, USA) in their anterior perirectal fat immediately prior to the first HDR BT treatment and $5 \mathrm{~mL}$ PEG hydrogel prior to the second HDR BT treatment. They compared this to 100 patients treated without a tissue spacer. PEG hydrogel significantly increased the mean prostate-rectal separation (mean $\pm \mathrm{SD}$, $12 \pm 4 \mathrm{~mm}$ with gel vs $4 \pm 2 \mathrm{~mm}$ without gel, $P<0.001)$ and significantly decreased rectal D2cc (47\% $\pm 9 \%$ with gel vs $60 \% \pm 8 \%$ without gel, $P<0.001)$. There were no significant differences in pain between patients who did and did not receive PEG hydrogel, and 3\% of gel patients developed prostatitis/epididymitis. However, no patients who received gel and HDR BT experienced infections when ceftriaxone and gentamicin were prescribed. While this report focused on EBRT in combination with HDR BT, other investigations of synthetic hydrogels have been published with other radiation therapy modalities, including low dose rate $\mathrm{BT}^{67,68}$ and stereotactic body radiation therapy (SBRT) ${ }^{69}$ also with promising results.

Whereas the aforementioned studies focused primarily on the safety and efficacy of spacer placement, rectal toxicity rates have been reported with various RT modalities. Uhl et a $7^{70}$ performed a phase II trial that included 52 men who received transperineal injection of SpaceOAR (Augmenix, Waltham, MA, USA) (Figure 3) prior to IMRT to $78 \mathrm{~Gy}$. Six patients (12\%) experienced acute GI Grade 2 toxicity, with no patients experiencing Grade 3 or 4 toxicity. In addition, no patient had GI toxicity Grade $\geq 2$ after 12 months. A separate prospective analysis was published by Eckert et $\mathrm{al}^{71}$ in which 11 patients had undergone SpaceOAR injection prior to IMRT to 78 Gy. Radiation treatment planning showed low rectal doses despite dose escalation to the prostate. This resulted in mild acute rectal toxicity without Grade 2 events and they revealed complete resolution of the GI rectal toxicities within 4-12 weeks. Last, a matched-pair analysis investigating QOL after prostate IMRT found that patients treated after SpaceOAR injection had lesser changes in their baseline Expanded Prostate Cancer Index Composite bowel bother scores when compared with their matched-pair cohorts. ${ }^{72}$ 


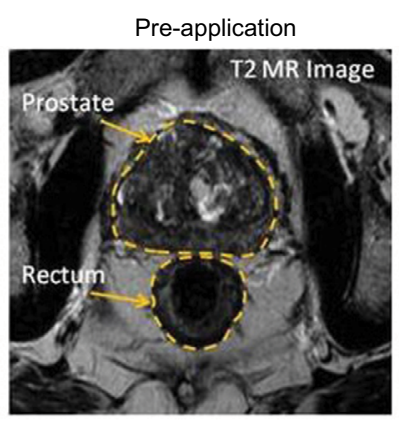

Post EBRT (3 months postapplication)

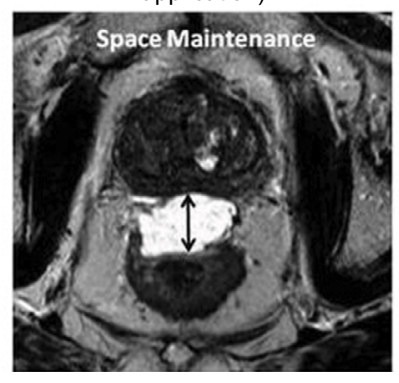

Figure 3 This material is injected in liquid form into the space between the rectum and prostate, where it hardens into a biodegradable gel, creating a separation between the posterior prostate and anterior rectal wall, thereby lowering the dose to the rectum. Used with permission from Augmenix, Inc. [homepage on the internet]. Bedford, MA, USA: SpaceOAR ${ }^{\circledast}$ system - spacing organs at risk. Available from: http://review.augmenix.com/products/spaceoar/. ${ }^{110}$

With today's IMRT techniques, rectal toxicities are relatively low and, thus, adding tissue spacers to IMRT may have little additional reduction of rectal toxicity. However, these tissue spacers may be more beneficial in men receiving higher doses per fraction such as those on SBRT protocols. SBRT typically involves doses $>5$ Gy per fraction. Multiple phase I and II trials with small numbers of patients have been reported that examined the role of SBRT in prostate cancer. ${ }^{73-78}$ In these studies, the Grade $\geq 2$ GI toxicity rates ranged from 0 to $12 \%$. However, in a phase I dose-escalation trial, ${ }^{79}$ grades 3-4 rectal toxicity was observed in $6.6 \%$ of patients enrolled in the highest dose level - 50 Gy in 5 fractions. The risk of toxicity increased when the rectal volume receiving 50 Gy exceeded $3 \mathrm{cc}$ and when $>35 \%$ of the rectal wall received 39 Gy. Despite this need to reduce rectal dose during SBRT delivery, few studies have been published examining the role of tissue spacers with SBRT. Alongi et $\mathrm{al}^{69}$ performed a phase I-II trial of SBRT in 40 patients. Within this cohort of patients, 8 patients underwent SpaceOAR injection prior to SBRT. No Grade $\geq 3$ toxicities were reported in the SpaceOAR patients; however, the median follow-up was only 11 months.

Fortunately, we now have a recently published phase III randomized trial that examined the role of SpaceOAR with median follow-up of three years in patients receiving conventionally fractionated RT. Hamstra et a ${ }^{80}$ enrolled 222 men that were randomized 2:1 to the spacer or control group. All patients received 79.2 Gy in 1.8-Gy fractions to the prostate and SVs, if indicated. The patients were blinded to the treatment allocation. The primary endpoint is the proportion of subjects with $>25 \%$ reduction in rectal V70, relative to the control group, together with the incidence of clinical rectal toxicity as a secondary endpoint. With a three-year follow-up, those with the hydrogel had a smaller volume of rectum treated to all volumes from V50 to V80 $(P<0.0001)$. Grade $\geq 1$ rectal toxicity decreased by $75 \%$ in the spacer arm $(P<0.03$; HR $0.24,95 \%$ CI $0.06-0.97$ ), and no Grade $\geq 2$ rectal toxicity was observed in the spacer arm (control: $6 \%$, vs spacer: $0 \% ; P<$ 0.015 ). With regard to bowel QOL, the investigators found that the spacer-arm bowel QOL score was near, or greater than, the baseline score but had declined significantly in the control arm, indicating worsening QOL without the spacer.

\section{Systemic agents}

The molecular and cellular events leading to late toxicity after RT begin virtually immediately after the first exposure to ionizing radiation. Vascular damage is important in the phenotype of RT-induced rectal injury, where telangiectatic vessels are often responsible for the bleeding characteristic of this condition. The cholesterol-lowering agents - HMG-CoA reductase inhibitors (statins) - have been demonstrated to reduce the risk of myocardial infarction, in part, through their vascular protective effects. In vitro, statins have been shown to protect human endothelial cells from ionizing radiation. ${ }^{81-83}$ Multiple mechanisms appear to be involved, including attenuation of extracellular stress responses, ${ }^{84,85}$ downregulation of chemokines and chemokine receptors, ${ }^{86}$ and exerting antiinflammatory and antithrombotic effects ${ }^{81,87-89}$ on these cells.

Wedlake et a ${ }^{10}$ performed a retrospective analysis of 308 patients treated for various pelvic malignancies, including prostate cancer. They found that the use of statins alone or in combination with angiotensin-converting enzyme inhibitors during radiotherapy was associated with reduced GI toxicities, both acutely and at 1 year after radiotherapy. The authors suggested a stronger protective effect from the nonlipophilic statin, pravastatin, as this class of statins is not cleared as readily by the liver in contrast to the lipophilic statins, and concentrates more readily in peripheral tissues.

Palumbo et $\mathrm{al}^{91}$ enrolled 195 patients into a prospective trial in which patients received $74.25 \mathrm{~Gy}$ in 33 fractions to the prostate and, if involved, to the SVs with IMRT. They assessed for acute rectal side effects weekly during RT and at 1 and 3 months after treatment. Late rectal side effects and disease status were monitored every 4-6 months for the 
first 5 years, and then annually. The authors observed which patients had been on antihypertensives, statins, or both during their course of RT. They found that the majority of patients (137/195; 70.26\%) were taking antihypertensive drugs; 42 patients $(27.69 \%)$ were on calcium channel blockers; and 55 patients $(28.21 \%)$ were on statins. Univariate analysis showed that statins and calcium channel blockers significantly reduced the rate of acute rectal toxicity, while multivariate analysis confirmed that only statins were an independent protective factor. Although these results are intriguing, the statins were not given in a randomized prospective manner; thus, additional studies are needed to confirm this benefit.

Anscher et $\mathrm{al}^{92}$ performed a prospective phase II trial evaluating the ability of statins to protect against the development of late rectal injury in a group of patients receiving highdose RT for prostate cancer. Lovastatin was the HMG-CoA reductase inhibitor used in this study and was administered concurrently for 1 year. Fifty-three patients were enrolled and evaluable at the end of the study. Patients could receive EBRT, BT, or a combination of both. EBRT was given with both 3DCRT and IMRT. Patients receiving adjuvant or salvage RT after prostatectomy were also enrolled. To be eligible for the study, a portion of the rectum had to receive at least $60 \mathrm{~Gy}$. The authors looked at all late rectal toxicities and found that 20/53 (38\%) patients developed Grade $\geq 2$ late rectal toxicity during the 2-year follow-up period after RT. This incidence was not lower than the anticipated incidence of $30 \%$ based on the literature available at the time of study implementation. The authors concluded that lovastatin was not effective as an agent to reduce the frequency and severity of late RT-induced rectal injury. However, based on preclinical data, other more potent members of the HMG-CoA reductase inhibitor class deserve further study as radiation protectors, especially with the implementation of IMRT.

\section{Conclusion}

Many technological advances have occurred over the past two decades that have allowed radiation oncologists to safely escalate the doses needed for prostate cancer while sparing acute and late rectal toxicities. We now have published dose-volume constraints that can prevent rectal injury and the use of IMRT, in combination with IGRT, which has led to significant reductions in these toxicities. Endorectal balloons have been studied in patients receiving both 3DCRT and IMRT. However, the recommendation for their use remains controversial, with some studies showing successful reduction of rectal toxicities but with others revealing no difference when compared to patients without balloons. Tissue spacers involve injecting a biodegradable material into the rectoprostatic fascia to physically move the prostate away from the rectal wall. The use of these spacers is promising as they show significant reduction in acute and late toxicities. However, longer follow-up is needed, as there is currently only one published phase III trial with a 3-year follow-up. Last, systemic agents such as statins and antihypertensives have been studied as radioprotectors of late rectal injury. The retrospective studies on this topic are promising, but additional prospective data is needed before this can be recommended to all patients undergoing RT for prostate cancer.

\section{Disclosure}

The authors report no conflicts of interest in this work.

\section{References}

1. Emami B, Lyman J, Brown A, et al. Tolerance of normal tissue to therapeutic irradiation. Int J Radiat Oncol Biol Phys. 1991;21(1):109-122.

2. Hauer-Jensen M, Wang J, Denham JW. Bowel injury: current and evolving management strategies. Semin Radiat Oncol. 2003;13(3):357-371

3. Buchi K. Radiation proctitis: therapy and prognosis. JAMA. 1991; 265(9):1180.

4. Hasleton PS, Carr N, Schofield PF. Vascular changes in radiation bowel disease. Histopathology. 1985;9(5):517-534.

5. Fajardo LF. The pathology of ionizing radiation as defined by morphologic patterns. Acta Oncol. 2005;44(1):13-22.

6. Zelefsky MJ, Fuks Z, Happersett L, et al. Clinical experience with intensity modulated radiation therapy (IMRT) in prostate cancer. Radiother Oncol. 2000;55(3):241-249.

7. Zietman AL, DeSilvio ML, Slater JD, et al. Comparison of conventional-dose vs high-dose conformal radiation therapy in clinically localized adenocarcinoma of the prostate: a randomized controlled trial. JAMA. 2005;294(10):1233-1239.

8. Merrick GS, Wallner KE, Butler WM, Blasko JC. Permanent prostate brachytherapy: is supplemental external-beam radiation therapy necessary? Oncology (Williston Park). 2006;20(5):514-522; discussion 522-525.

9. Morris WJ, Tyldesley S, Rodda S, et al. Androgen suppression combined with elective nodal and dose escalated radiation therapy (the ASCENDE-RT Trial): an analysis of survival endpoints for a randomized trial comparing a low-dose-rate brachytherapy boost to a dose-escalated external beam boost for high- and intermediaterisk prostate cancer. Int J Radiat Oncol Biol Phys. 2017;98(2): 275-285.

10. Giordano SH, Lee A, Kuo YF, Freeman J, Goodwin JS. Late gastrointestinal toxicity after radiation for prostate cancer. Cancer. 2006;107(2):423-432.

11. Al-Mamgani A, van Putten WL, Heemsbergen WD, et al. Update of Dutch multicenter dose-escalation trial of radiotherapy for localized prostate cancer. Int J Radiat Oncol Biol Phys. 2008;72(4):980-988.

12. Dearnaley DP, Sydes MR, Graham JD, et al; RT01 collaborators. Escalated-dose versus standard-dose conformal radiotherapy in prostate cancer: first results from the MRC RT01 randomised controlled trial. Lancet Oncol. 2007;8(6):475-487.

13. Kuban DA, Tucker SL, Dong L, et al. Long-term results of the M. D. Anderson randomized dose-escalation trial for prostate cancer. Int $J$ Radiat Oncol Biol Phys. 2008;70(1):67-74.

14. Zelefsky MJ, Levin EJ, Hunt M, et al. Incidence of late rectal and urinary toxicities after three-dimensional conformal radiotherapy and intensity-modulated radiotherapy for localized prostate cancer. Int $J$ Radiat Oncol Biol Phys. 2008;70(4):1124-1129. 
15. Alicikus ZA, Yamada Y, Zhang Z, et al. Ten-year outcomes of highdose, intensity-modulated radiotherapy for localized prostate cancer. Cancer. 2011;117(7):1429-1437.

16. Peeters ST, Heemsbergen WD, van Putten WL, et al. Acute and late complications after radiotherapy for prostate cancer: results of a multicenter randomized trial comparing 68 Gy to 78 Gy. Int J Radiat Oncol Biol Phys. 2005;61(4):1019-1034.

17. Boyer AL, Antonuk L, Fenster A, et al. A review of electronic portal imaging devices (EPIDs). Med Phys. 1992;19(1):1-16.

18. Kessler ML, McShan DL, Fraass BA. A computer-controlled conformal radiotherapy system. III: graphical simulation and monitoring of treatment delivery. Int J Radiat Oncol Biol Phys. 1995;33(5):1173-1180.

19. Jaffray DA, Siewerdsen JH, Wong JW, Martinez AA. Flat-panel conebeam computed tomography for image-guided radiation therapy. Int J Radiat Oncol Biol Phys. 2002;53(5):1337-1349.

20. Lu W, Olivera GH, Chen Q, et al. Deformable registration of the planning image (kVCT) and the daily images (MVCT) for adaptive radiation therapy. Phys Med Biol. 2006;51(17):4357-4374.

21. Shirato H, Harada T, Harabayashi T, et al. Feasibility of insertion/ implantation of 2.0-mm-diameter gold internal fiducial markers for precise setup and real-time tumor tracking in radiotherapy. Int J Radiat Oncol Biol Phys. 2003;56(1):240-247.

22. Balter JM, Wright JN, Newell LJ, et al. Accuracy of a wireless localization system for radiotherapy. Int J Radiat Oncol Biol Phys. 2005;61(3):933-937.

23. Rajendran RR, Plastaras JP, Mick R, McMichael Kohler D, Kassaee A, Vapiwala N. Daily isocenter correction with electromagnetic-based localization improves target coverage and rectal sparing during prostate radiotherapy. Int J Radiat Oncol Biol Phys. 2010;76(4):1092-1099.

24. Chung HT, Xia P, Chan LW, Park-Somers E, Roach M 3rd. Does imageguided radiotherapy improve toxicity profile in whole pelvic-treated high-risk prostate cancer? Comparison between IG-IMRT and IMRT. Int J Radiat Oncol Biol Phys. 2009;73(1):53-60.

25. Fiorino C, Valdagni R, Rancati T, Sanguineti G. Dose-volume effects for normal tissues in external radiotherapy: pelvis. Radiother Oncol. 2009;93(2):153-167.

26. Jackson A, Skwarchuk MW, Zelefsky MJ, et al. Late rectal bleeding after conformal radiotherapy of prostate cancer. II. Volume effects and dose-volume histograms. Int J Radiat Oncol Biol Phys. 2001;49(3):685-698.

27. Fiorino C, Cozzarini C, Vavassori V, et al. Relationships between DVHs and late rectal bleeding after radiotherapy for prostate cancer: analysis of a large group of patients pooled from three institutions. Radiother Oncol. 2002;64(1):1-12.

28. Fiorino C, Sanguineti G, Cozzarini C, et al. Rectal dose-volume constraints in high-dose radiotherapy of localized prostate cancer. Int J Radiat Oncol Biol Phys. 2003;57(4):953-962.

29. Rancati T, Fiorino C, Gagliardi G, et al. Fitting late rectal bleeding data using different NTCP models: results from an Italian multi-centric study (AIROPROS0101). Radiother Oncol. 2004;73(1):21-32.

30. Vargas C, Martinez A, Kestin LL, et al. Dose-volume analysis of predictors for chronic rectal toxicity after treatment of prostate cancer with adaptive image-guided radiotherapy. Int J Radiat Oncol Biol Phys. 2005;62(5):1297-1308.

31. Söhn M, Yan D, Liang J, Meldolesi E, Vargas C, Alber M. Incidence of late rectal bleeding in high-dose conformal radiotherapy of prostate cancer using equivalent uniform dose-based and dose-volume-based normal tissue complication probability models. Int $J$ Radiat Oncol Biol Phys. 2007;67(4):1066-1073.

32. Fiorino C, Fellin G, Rancati T, et al. Clinical and dosimetric predictors of late rectal syndrome after 3D-CRT for localized prostate cancer: preliminary results of a multicenter prospective study. Int J Radiat Oncol Biol Phys. 2008;70(4):1130-1137.

33. Storey MR, Pollack A, Zagars G, Smith L, Antolak J, Rosen I. Complications from radiotherapy dose escalation in prostate cancer: preliminary results of a randomized trial. Int J Radiat Oncol Biol Phys. 2000;48(3):635-642.
34. Huang EH, Pollack A, Levy L, et al. Late rectal toxicity: dose-volume effects of conformal radiotherapy for prostate cancer. Int J Radiat Oncol Biol Phys. 2002;54(5):1314-1321.

35. van der Laan HP, van den Bergh A, Schilstra C, Vlasman R, Meertens $\mathrm{H}$, Langendijk JA. Grading-system-dependent volume effects for late radiation-induced rectal toxicity after curative radiotherapy for prostate cancer. Int J Radiat Oncol Biol Phys. 2008;70(4):1138-1145.

36. Peeters ST, Hoogeman MS, Heemsbergen WD, Hart AA, Koper PC, Lebesque JV. Rectal bleeding, fecal incontinence, and high stool frequency after conformal radiotherapy for prostate cancer: normal tissue complication probability modeling. Int J Radiat Oncol Biol Phys. 2006;66(1):11-19.

37. Michalski JM, Winter K, Purdy JA, et al. Toxicity after three-dimensional radiotherapy for prostate cancer with RTOG 9406 dose level IV. Int J Radiat Oncol Biol Phys. 2004;58(3):735-742.

38. Peeters ST, Hoogeman MS, Heemsbergen WD, et al. Volume and hormonal effects for acute side effects of rectum and bladder during conformal radiotherapy for prostate cancer. Int J Radiat Oncol Biol Phys. 2005;63(4):1142-1152.

39. Schaake W, van der Schaaf A, van Dijk LV, Bongaerts AH, van den Bergh AC, Langendijk JA. Normal tissue complication probability (NTCP) models for late rectal bleeding, stool frequency and fecal incontinence after radiotherapy in prostate cancer patients. Radiother Oncol. 2016;119(3):381-387.

40. Mirjolet C, Walker PM, Gauthier M, et al. Absolute volume of the rectum and AUC from rectal DVH between 25Gy and 50Gy predict acute gastrointestinal toxicity with IG-IMRT in prostate cancer. Radiat Oncol. 2016;11(1):145.

41. Dréan G, Acosta O, Ospina JD, et al. Identification of a rectal subregion highly predictive of rectal bleeding in prostate cancer IMRT. Radiother Oncol. 2016;119(3):388-397.

42. Brenner DJ, Martinez AA, Edmundson GK, Mitchell C, Thames HD, Armour EP. Direct evidence that prostate tumors show high sensitivity to fractionation (low alpha/beta ratio), similar to late-responding normal tissue. Int J Radiat Oncol Biol Phys. 2002;52(1):6-13.

43. Miralbell R, Roberts SA, Zubizarreta E, Hendry JH. Dose-fractionation sensitivity of prostate cancer deduced from radiotherapy outcomes of 5,969 patients in seven international institutional datasets: $\alpha / \beta=1.4$ (0.9-2.2) Gy. Int J Radiat Oncol Biol Phys. 2012;82(1):e17-e24.

44. Thames HD, Bentzen SM, Turesson I, Overgaard M, Van den Bogaert W. Time-dose factors in radiotherapy: a review of the human data. Radiother Oncol. 1990;19(3):219-235.

45. Dearnaley D, Syndikus I, Mossop H, et al; CHHiP Investigators. Conventional versus hypofractionated high-dose intensity-modulated radiotherapy for prostate cancer: 5-year outcomes of the randomised, noninferiority, phase 3 CHHiP trial. Lancet Oncol. 2016;17(8):1047-1060.

46. Lee WR, Dignam JJ, Amin MB, et al. Randomized phase III oninferiority study comparing two radiotherapy fractionation schedules in patients with low-risk prostate cancer. J Clin Oncol. 2016;34(20):2325-2332.

47. Catton CN, Lukka H, Gu CS, et al. Randomized trial of a hypofractionated radiation regimen for the treatment of localized prostate cancer. J Clin Oncol. 2017;35(17):1884-1890.

48. Incrocci L, Wortel RC, Alemayehu WG, et al. Hypofractionated versus conventionally fractionated radiotherapy for patients with localised prostate cancer (HYPRO): final efficacy results from a randomised, multicentre, open-label, phase 3 trial. Lancet Oncol. 2016;17(8):1061-1069.

49. Benjamin LC, Tree AC, Dearnaley DP. The role of hypofractionated radiotherapy in prostate cancer. Curr Oncol Rep. 2017;19(4):30.

50. D'Amico AV, Manola J, Loffredo M, et al. A practical method to achieve prostate gland immobilization and target verification for daily treatment. Int J Radiat Oncol Biol Phys. 2001;51(5):1431-1436.

51. McGary JE, Teh BS, Butler EB, Grant W 3rd. Prostate immobilization using a rectal balloon. J Appl Clin Med Phys. 2002;3(1):6-11.

52. Teh BS, Woo SY, Mai WY, et al. Clinical experience with intensitymodulated radiation therapy (IMRT) for prostate cancer with the use of rectal balloon for prostate immobilization. Med Dosim. 2002;27(2):105-113. 
53. van Lin EN, van der Vight LP, Witjes JA, Huisman HJ, Leer JW, Visser AG. The effect of an endorectal balloon and off-line correction on the interfraction systematic and random prostate position variations: a comparative study. Int J Radiat Oncol Biol Phys. 2005;61(1): $278-288$.

54. El-Bassiouni M, Davis JB, El-Attar I, Studer GM, Lütolf UM, Ciernik IF. Target motion variability and on-line positioning accuracy during external-beam radiation therapy of prostate cancer with an endorectal balloon device. Strahlenther Onkol. 2006;182(9):531-536.

55. Wachter S, Gerstner N, Dorner D, et al. The influence of a rectal balloon tube as internal immobilization device on variations of volumes and dose-volume histograms during treatment course of conformal radiotherapy for prostate cancer. Int J Radiat Oncol Biol Phys. 2002;52(1):91-100.

56. Hille A, Schmidberger H, Töws N, Weiss E, Vorwerk H, Hess CF. The impact of varying volumes in rectal balloons on rectal dose sparing in conformal radiation therapy of prostate cancer. A prospective threedimensional analysis. Strahlenther Onkol. 2005;181(11):709-716.

57. Elsayed H, Bölling T, Moustakis C, et al. Organ movements and dose exposures in teletherapy of prostate cancer using a rectal balloon. Strahlenther Onkol. 2007;183(11):617-624.

58. Patel RR, Orton N, Tome WA, Chappell R, Ritter MA. Rectal dose sparing with a balloon catheter and ultrasound localization in conformal radiation therapy for prostate cancer. Radiother Oncol. 2003 67(3):285-294.

59. van Lin EN, Hoffmann AL, van Kollenburg P, Leer JW, Visser AG. Rectal wall sparing effect of three different endorectal balloons in 3D conformal and IMRT prostate radiotherapy. Int J Radiat Oncol Biol Phys. 2005;63(2):565-576

60. van Lin EN, Kristinsson J, Philippens ME, et al. Reduced late rectal mucosal changes after prostate three-dimensional conformal radiotherapy with endorectal balloon as observed in repeated endoscopy. Int J Radiat Oncol Biol Phys. 2007;67(3):799-811.

61. Schutzer ME, Orio PF, Biagioli MC, Asher DA, Lomas H, Moghanaki D. A review of rectal toxicity following permanent low dose-rate prostate brachytherapy and the potential value of biodegradable rectal spacers. Prostate Cancer Prostatic Dis. 2015;18(2):96-103.

62. Prada PJ, Gonzalez H, Menéndez C, et al. Transperineal injection of hyaluronic acid in the anterior perirectal fat to decrease rectal toxicity from radiation delivered with low-dose-rate brachytherapy for prostate cancer patients. Brachytherapy. 2009;8(2):210-217.

63. Noyes WR, Hosford CC, Schultz SE. Human collagen injections to reduce rectal dose during radiotherapy. Int J Radiat Oncol Biol Phys. 2012;82(5):1918-1922.

64. Melchert C, Gez E, Bohlen G, et al. Interstitial biodegradable balloon for reduced rectal dose during prostate radiotherapy: results of a virtual planning investigation based on the pre- and post-implant imaging data of an international multicenter study. Radiother Oncol. 2013;106(2):210-214.

65. Susil RC, McNutt TR, DeWeese TL, Song D. Effects of prostate-rectum separation on rectal dose from external beam radiotherapy. Int J Radiat Oncol Biol Phys. 2010;76(4):1251-1258.

66. Strom TJ, Wilder RB, Fernandez DC, et al. A dosimetric study of polyethylene glycol hydrogel in 200 prostate cancer patients treated with high-dose rate brachytherapy \pm intensity modulated radiation therapy. Radiother Oncol. 2014;111(1):126-131.

67. Beydoun N, Bucci JA, Chin YS, Malouf D, Enari E, Painter SD. First report of transperineal polyethylene glycol hydrogel spacer use to curtail rectal radiation dose after permanent iodine-125 prostate brachytherapy. Brachytherapy. 2013;12(4):368-374.

68. Mahal BA, Ziehr DR, Hyatt AS, et al. Use of a rectal spacer with low-dose-rate brachytherapy for treatment of prostate cancer in previously irradiated patients: initial experience and short-term results. Brachytherapy. 2014;13(5):442-449.

69. Alongi F, Cozzi L, Arcangeli S, et al. Linac based SBRT for prostate cancer in 5 fractions with VMAT and flattening filter free beams: preliminary report of a phase II study. Radiat Oncol. 2013;8:171.
70. Uhl M, van Triest B, Eble MJ, Weber DC, Herfarth K, De Weese TL. Low rectal toxicity after dose escalated IMRT treatment of prostate cancer using an absorbable hydrogel for increasing and maintaining space between the rectum and prostate: results of a multi-institutional phase II trial. Radiother Oncol. 2013;106(2):215-219.

71. Eckert F, Alloussi S, Paulsen F, et al. Prospective evaluation of a hydrogel spacer for rectal separation in dose-escalated intensity-modulated radiotherapy for clinically localized prostate cancer. BMC Cancer. 2013;13:27.

72. Pinkawa M, Piroth MD, Holy R, et al. Quality of life after intensitymodulated radiotherapy for prostate cancer with a hydrogel spacer. Matched-pair analysis. Strahlenther Onkol. 2012;188(10):917-925.

73. Madsen BL, Hsi RA, Pham HT, Fowler JF, Esagui L, Corman J. Stereotactic hypofractionated accurate radiotherapy of the prostate (SHARP), 33.5 Gy in five fractions for localized disease: first clinical trial results. Int J Radiat Oncol Biol Phys. 2007;67(4):1099-1105.

74. McBride SM, Wong DS, Dombrowski JJ, et al. Hypofractionated stereotactic body radiotherapy in low-risk prostate adenocarcinoma: preliminary results of a multi-institutional phase 1 feasibility trial. Cancer. 2012;118(15):3681-3690.

75. Katz A, Kang J. Stereotactic body radiotherapy with or without external beam radiation as treatment for organ confined high-risk prostate carcinoma: a six year study. Radiat Oncol. 2014;9:1.

76. Loblaw A, Cheung P, D'Alimonte L, et al. Prostate stereotactic ablative body radiotherapy using a standard linear accelerator: toxicity, biochemical, and pathological outcomes. Radiother Oncol. 2013;107(2):153-158.

77. Kang JK, Cho CK, Choi CW, et al. Image-guided stereotactic body radiation therapy for localized prostate cancer. Tumori. 2011;97(1): 43-48.

78. Freeman DE, King CR. Stereotactic body radiotherapy for low-risk prostate cancer: five-year outcomes. Radiat Oncol. 2011;6:3.

79. Kim DW, Cho LC, Straka C, et al. Predictors of rectal tolerance observed in a dose-escalated phase 1-2 trial of stereotactic body radiation therapy for prostate cancer. Int J Radiat Oncol Biol Phys. 2014;89(3):509-517.

80. Hamstra DA, Mariados N, Sylvester J, et al. Continued benefit to rectal separation for prostate radiation therapy: final results of a phase III trial. Int J Radiat Oncol Biol Phys. 2017;97(5):976-985.

81. Boerma M, Burton GR, Wang J, Fink LM, McGehee RE Jr, HauerJensen M. Comparative expression profiling in primary and immortalized endothelial cells: changes in gene expression in response to hydroxy methylglutaryl-coenzyme A reductase inhibition. Blood Coagul Fibrinolysis. 2006;17(3):173-180.

82. Gaugler MH, Vereycken-Holler V, Squiban C, Vandamme M, VozeninBrotons MC, Benderitter M. Pravastatin limits endothelial activation after irradiation and decreases the resulting inflammatory and thrombotic responses. Radiat Res. 2005;163(5):479-487.

83. Nübel T, Damrot J, Roos WP, Kaina B, Fritz G. Lovastatin protects human endothelial cells from killing by ionizing radiation without impairing induction and repair of DNA double-strand breaks. Clin Cancer Res. 2006;12(3 Pt 1):933-939.

84. Rikitake Y, Kawashima S, Takeshita S, et al. Anti-oxidative properties of fluvastatin, an HMG-CoA reductase inhibitor, contribute to prevention of atherosclerosis in cholesterol-fed rabbits. Atherosclerosis. 2001;154(1):87-96.

85. Morikawa S, Takabe W, Mataki C, et al. The effect of statins on mRNA levels of genes related to inflammation, coagulation, and vascular constriction in HUVEC. Human umbilical vein endothelial cells. $J$ Atheroscler Thromb. 2002;9(4):178-183.

86. Waehre T, Damås JK, Gullestad L, et al. Hydroxymethylglutaryl coenzyme a reductase inhibitors down-regulate chemokines and chemokine receptors in patients with coronary artery disease. J Am Coll Cardiol. 2003;41(9):1460-1467.

87. Undas A, Brozek J, Musial J. Anti-inflammatory and antithrombotic effects of statins in the management of coronary artery disease. Clin Lab. 2002;48(5-6):287-296. 
88. Shi J, Wang J, Zheng H, et al. Statins increase thrombomodulin expression and function in human endothelial cells by a nitric oxidedependent mechanism and counteract tumor necrosis factor alphainduced thrombomodulin downregulation. Blood Coagul Fibrinolysis. 2003;14(6):575-585.

89. Pérez-Guerrero C, Alvarez de Sotomayor M, Jimenez L, Herrera MD, Marhuenda E. Effects of simvastatin on endothelial function after chronic inhibition of nitric oxide synthase by L-NAME. J Cardiovasc Pharmacol. 2003;42(2):204-210.

90. Wedlake LJ, Silia F, Benton B, et al. Evaluating the efficacy of statins and ACE-inhibitors in reducing gastrointestinal toxicity in patients receiving radiotherapy for pelvic malignancies. Eur $J$ Cancer. 2012;48(14):2117-2124.

91. Palumbo I, Matrone F, Montesi G, et al. Statins protect against acute RT-related rectal toxicity in patients with prostate cancer: an observational prospective study. Anticancer Res. 2017;37(3):1453-1457.

92. Anscher MS, Chang MG, Moghanaki D, et al. A phase II study to prevent radiation-induced rectal injury with lovastatin. Am J Clin Oncol. Epub 2016 July 19.

93. Sarosdy MF. Urinary and rectal complications of contemporary permanent transperineal brachytherapy for prostate carcinoma with or without external beam radiation therapy. Cancer. 2004;101(4):754-760.

94. Akimoto T, Muramatsu H, Takahashi M, et al. Rectal bleeding after hypofractionated radiotherapy for prostate cancer: correlation between clinical and dosimetric parameters and the incidence of grade 2 or worse rectal bleeding. Int J Radiat Oncol Biol Phys. 2004;60(4):1033-1039.

95. Lee CM, Lee RJ, Handrahan DL, Sause WT. Comparison of late rectal toxicity from conventional versus three-dimensional conformal radiotherapy for prostate cancer: analysis of clinical and dosimetric factors. Urology. 2005;65(1):114-119.

96. Sherertz T, Wallner K, Merrick G, et al. Factors predictive of rectal bleeding after 103Pd and supplemental beam radiation for prostate cancer. Brachytherapy. 2004;3(3):130-135.

97. Tucker SL, Dong L, Cheung R, et al. Comparison of rectal dose-wall histogram versus dose-volume histogram for modeling the incidence of late rectal bleeding after radiotherapy. Int J Radiat Oncol Biol Phys. 2004;60(5):1589-1601.

98. Waterman FM, Dicker AP. Probability of late rectal morbidity in 125I prostate brachytherapy. Int J Radiat Oncol Biol Phys. 2003;55(2): $342-353$.
99. Yoshioka Y, Nose T, Yoshida K, et al. High-dose-rate brachytherapy as monotherapy for localized prostate cancer: a retrospective analysis with special focus on tolerance and chronic toxicity. Int J Radiat Oncol Biol Phys. 2003;56(1):213-220.

100. Albert M, Tempany CM, Schultz D, et al. Late genitourinary and gastrointestinal toxicity after magnetic resonance image-guided prostate brachytherapy with or without neoadjuvant external beam radiation therapy. Cancer. 2003;98(5):949-954.

101. Ryu JK, Winter K, Michalski JM, et al. Interim report of toxicity from 3D conformal radiation therapy (3D-CRT) for prostate cancer on 3DOG/RTOG 9406, level III (79.2 Gy). Int J Radiat Oncol Biol Phys. 2002;54(4):1036-1046.

102. Skwarchuk MW, Jackson A, Zelefsky MJ, et al. Late rectal toxicity after conformal radiotherapy of prostate cancer (I): multivariate analysis and dose-response. Int J Radiat Oncol Biol Phys. 2000;47(1):103-113.

103. Hoffman KE, Skinner H, Pugh TJ, et al. Patient-reported urinary, bowel, and sexual function after hypofractionated intensity-modulated radiation therapy for prostate cancer: results from a randomized trial. Am J Clin Oncol. Epub 2016 Sep 15.

104. Pollack A, Walker G, Horwitz EM, et al. Randomized trial of hypofractionated external-beam radiotherapy for prostate cancer. $J$ Clin Oncol. 2013;31(31):3860-3868.

105. Katz AJ, Kang J. Quality of life and toxicity after SBRT for organconfined prostate cancer, a 7-year study. Front Oncol. 2014;4:301.

106. Chen LN, Suy S, Uhm S, et al. Stereotactic body radiation therapy (SBRT) for clinically localized prostate cancer: the Georgetown University experience. Radiat Oncol. 2013;8:58.

107. King CR, Brooks JD, Gill H, Presti JC Jr. Long-term outcomes from a prospective trial of stereotactic body radiotherapy for low-risk prostate cancer. Int J Radiat Oncol Biol Phys. 2012;82(2):877-882.

108. World Endoscopy Organization [homepage on the Internet]. Radiation proctitis; 2012 [cited December 25, 2012]. Available from: http://www. endoatlas.org/index.php?page $=$ results_jquery\&mstcat $=3$. Accessed July 14, 2017.

109. Lang S, Riesterer O. Progress in Physics: Modern Techniques in Radiation Oncology. SPG Mitteilungen. 2013;41(36):19-22.

110. Augmenix, Inc. [homepage on the internet]. Bedford, MA, USA: SpaceOAR ${ }^{\circledR}$ system - spacing organs at risk. Available from: http:// review.augmenix.com/products/spaceoar/. Accessed April 5, 2017.
Cancer Management and Research

\section{Publish your work in this journal}

Cancer Management and Research is an international, peer-reviewed open access journal focusing on cancer research and the optimal use of preventative and integrated treatment interventions to achieve improved outcomes, enhanced survival and quality of life for the cancer patient. The manuscript management system is completely online and includes

\section{Dovepress}

a very quick and fair peer-review system, which is all easy to use. Visit http://www.dovepress.com/testimonials.php to read real quotes from published authors. 